\title{
Reaching out to migrant and refugee communities to support home language maintenance
}

\begin{abstract}
Migrant and refugee parents considering raising their children in their non-mainstream home language often fear that this decision may impact negatively on their children's English language ability and thus affect their academic prospects. The lack of institutional support for home languages in the Australian school system, and the well-intentioned but misguided advice parents may receive to switch to the mainstream language in family interactions, reinforce parents' doubts. To assuage parents' concerns and assist them in making an informed decision most appropriate for their family circumstances, we developed and delivered free workshops on bilingual upbringing. We also trained bilingual facilitators who adapted the workshops culturally and linguistically and conducted these in their own communities. This paper discusses these workshops, the feedback received, our observations, and lessons learned.
\end{abstract}

\section{Keywords}

Bilingualism, Community Languages, Language Attitudes, Language Maintenance

\section{Introduction}

Australia, like many Western countries, has a multicultural society. According to the latest census (2012), almost 6 million migrants born in over 200 countries now live in Australia, with 49 per cent of longer-standing migrants and 67 per cent of recent arrivals claiming a language other than English (Australian Bureau of Statistics 2012). Overall, 19 per cent of the population over the age of five years speaks a language other than English at home, with percentages higher in the largest urban centers. There is also great linguistic diversity, since, in addition to Aboriginal languages, over 300 languages are currently spoken in the country. This linguistic diversity extends into the school system: 11.8 per cent of the 23,745 children who completed the CensusAtSchool questionnaire (Australian Bureau of Statistics 2014) in 2013 were born overseas, and 24.8 per cent of respondents spoke a language other than English at home. ${ }^{1}$ In some geographical areas of Australia (e.g., Logan Central, neighboring

\footnotetext{
${ }^{1}$ Interestingly, of the three top languages, Arabic (1.4 per cent), Mandarin (1.3 per cent) and Cantonese (1.1 per cent), only Mandarin is taught in the state school system.
} 
Brisbane in Queensland), up to 70 per cent of the state school population come from nonEnglish speaking homes (Queensland Government 2009).

The substantial bi/multilingualism present in Australian society has not been acknowledged in language and literacy-related educational policies, which are still 'caught in the grip of the monolingual mindset' (Clyne 2007, 3.6), i.e., the pervasive view that monolingualism is the norm and bi/multilingualism the exception despite demographic evidence to the contrary. Moreover, an examination of Australian language and literacy-related education policies reveals that the position of languages other than English in the education system, in both rhetoric and implementation, became more precarious over time, to the extent that we now find a negative correlation. The more multilingual Australia has become, the more assimilationist its policies, and the more monolingual the orientation of the society that governments have sought to establish through policy (Schalley, Guillemin, and Eisenchlas 2016). ${ }^{2}$

The monolingual mindset evident in language and literacy-related educational policies runs counter to the massive body of research providing evidence of the cognitive, academic, affective, and social advantages that result from growing up bilingually with both home and mainstream languages (see Eisenchlas, Schalley and Guillemin 2013; Bialystok 2001). Here we mention just three findings that should be particularly relevant to educational policies: 1) Bilingual children have been found to have better metalinguistic awareness, including executive control and linguistic processing, than monolingual children (Cromdal 1999; Bialystock, Peets and Moreno 2014). Children who do well in metalinguistic tasks typically also learn to read quickly and easily. 2) Despite fears that the home language may have detrimental effects on acquisition of the mainstream language, there is growing evidence not only that home language maintenance supports mainstream language acquisition (Makin, Campbell and Jones Diaz 1995), but that children who are educated initially in their home language learn a second language, the majority language, more proficiently, and achieve more academic success than those who have not had such a solid language foundation (Barac and Bialystok 2011; Cummins 2000; Swain, Lapkin, Rowen and Hart 1990; Thomas and Collier 1997). 3) A bilingual upbringing is set to increase the student's sense of self-worth and the esteem in which they hold their heritage culture and language. Studies have shown

\footnotetext{
${ }^{2}$ The backlash against multilingualism in Australia and re-emergence of assimilationist attitudes have also been discussed by Scarino (2014) and Chiro (2014), among others.
} 
positive correlations between self-esteem and academic success (Makin et al. 1995; Wright and Taylor 1995).

We fully acknowledge that mastery of the English language by migrant and refugee children is crucial for their social and academic inclusion into Australian society. Yet it also needs to be noted that neglecting languages other than English in the education system renders at least the loss of valuable opportunities or worse, negative impacts. It can prevent or severely hinder the capacity of newly arrived children to achieve the many benefits associated with a bilingual upbringing. It also impacts negatively on home language maintenance by second and third generation migrants, as can be seen from high percentages of language attrition rates across generations documented in census data (Clyne 2001) ${ }^{3}$. Fishman (1991), Rosenthal and Cichello (1986) and other researchers have discussed how language shift can trigger a clash of values between newcomers and their offspring, resulting in intergenerational conflict and alienation, and diminished feelings of belonging.

We recognize that supporting home language maintenance and development in the varied range of languages in use in Australia poses a significant challenge to the formal education system, especially since for some of these languages there is a lack of trained educators and teaching materials, and the languages may have only small numbers of speakers in Australia. Furthermore, current assimilationist policy orientations repudiate the value of diverting resources from English language and literacy programs into supporting community languages, whose maintenance is seen as a threat to social cohesion. But even if there was the political will to support these languages, the capacity of the education system to respond is also doubtful.

Concerns identified by some scholars cast doubt on the ability of schools to cope with a complex linguistic situation such as that in Australia. For instance, Valdés (1995) argued that 'the classroom is limited in what can be accomplished against the assimilative pressures of the wider society' (p. 310). Baldauf (1993) concluded that the time required for learners to attain even minimal vocational proficiency may be beyond that which schools can provide.

\footnotetext{
${ }^{3}$ The census documents this process of home language attrition. According to the 2011 census data, while 53 percent of first generation Australians speak a language other than English at home, the proportion of second generation speakers is much lower at 20 percent, and lower still for the third-plus generation (1.6 percent). These figures provide evidence that despite what some opponents may claim, the home language is not a threat to English.
} 
Fishman (1991) recognized that schools alone cannot reverse language shift, and suggested steps for communities to create an environment in which minority languages can both grow and thrive beyond the classroom. Clyne (2005) similarly called for a collaborative approach involving government, schools, universities, communities, ethnic schools, and families.

Recognizing that in the prevailing politico-economic context a shift towards appreciating the value of community languages is unlikely, we understand that language and literacy-related educational policies in Australia are unlikely to be changed in the near future. We therefore have adopted a grassroots approach to supporting home language maintenance and focus our attention on the role of families in home language transmission. We believe that in light of the institutional neglect of home languages, parents and carers may need to take on this task themselves to cater for the linguistic needs of their children and promote linguistic development in the home language, motivated by the desire to maximize life opportunities for their children and enrich family life (cf. Seloni and Sarfati 2013).

Indeed, Clyne provided clear recommendations for families who seek to achieve these goals. Recommendations include: 1) developing a family language policy that is implemented consistently; 2) providing a communicative rich environment; and 3) providing resources and opportunities for language development (Clyne 2005, 180). To actually do so, however, parents need to be convinced of the value of a bilingual upbringing and feel confident in their decision to raise their children to be bilingual. While it has been recognised that parents may actively seek and find information about bilingualism from a diverse range of popular publications and websites (see King and Fogle 2006; Piller 2001), these sources at times present contradictory and even misleading information, which we aim to rectify through our work. To address that aim, we developed and conducted workshops on bilingualism which seek to support parents in making informed decisions about their children’s linguistic upbringing.

Between November 2011 and August 2016, we held 37 workshops in diverse venues (e.g., schools, child care centres, public libraries, community centres, churches) and to diverse audiences (e.g., families -including permanent and temporary migrants and refugees as well as second and third generation Australians-, teachers, child care workers, community liaison officers) and audience sizes (ranging from 8 to 150 participants per workshop). The workshops were delivered in diverse neighbourhoods, ranging from areas of high disadvantage to affluent areas, thus participants were a heterogeneous group with regards to 
socio-economic background, level of education, ethnicity, languages spoken at home, and proficiency in English. While participants in some workshops had a common linguistic background (e.g., Japanese, Samoan), most workshops included speakers of several different languages. For instance, one workshop delivered to newly-arrived refugees included speakers of around 40 languages, including two or three sign languages, and was simultaneously translated into around ten languages. With regards to gender composition of the audience, while child care workers and community liaison officers were almost exclusively female, a sizeable number of fathers attended the workshops. Overall, these workshops attracted over 1,000 participants.

In this paper, we focus on 'Should I speak English to my child?', a workshop we designed mainly for parents and carers ${ }^{4}$ who are considering raising their children in their home language but fear this decision may impede their children's development of English language. We discuss the project's rationale, the aims that guided its development, and workshop content. We then briefly evaluate the workshop in terms of parents' and carers' satisfaction. We finalize the paper with our reflection on observations and lessons learned, regarding both the workshop itself and the challenges that lie ahead.

\section{Rationale}

While it is widely acknowledged that parents play a crucial role in their children's linguistic development (Edwards and Newcombe 2005), migrant and refugee parents in Australia face a number of challenges in raising bilingual children. The Australian public discourse about bilingualism is generally averse, viewing the use of languages other than English as a potential source of sedition and social upheaval (cf. Lo Bianco 2003). The lack of support for bilingualism in mainstream society and educational institutions sends a clear message to parents that only some languages are valued (i.e., those seen as having economic or cultural relevance). Moreover, parents are still advised by some well-intended but ill-informed trusted stakeholders (e.g., teachers, speech pathologists, missionaries) to switch to the mainstream language - irrespective of their proficiency in that language - if they want their children to succeed academically.

\footnotetext{
${ }^{4}$ Although many participants were parents, attendance to the workshops also included grandparents, older siblings, community liaison officers who have frequent interaction with ethnic community members, as well as women involved in Family Day Care (a form of child care that is provided in the day care educators' own homes) who attended as part of their professional development.
} 
Regrettably, the massive body of research on the benefits and challenges of bilingualism has not generated a strong impact outside of academic circles. Thus, parents often feel ill prepared to make an informed decision about their children's linguistic upbringing and to withstand societal pressure if they do decide to maintain the home language. This decision becomes even harder when the home language has little prestige in the wider community, and when the cultural practices and norms of minority groups clash with mainstream educational practices. Our workshop aims to empower parents in making their decisions.

\section{Brief overview of the workshop}

Should I speak English to my child? is a workshop we developed as a first step to promote the benefits of bilingualism to parents and carers, ${ }^{5}$ and to support families and communities in home language maintenance and development. We have delivered the workshop since the end of 2011 as a free activity in libraries, primary and high schools, childcare centres, day care facilities, community centres, community events, professional development/training locations, ethnic schools, Technical and Further Education (TAFE) institutes and universities, across Brisbane, Gold Coast, Ipswich, Logan, and Toowoomba, all of which are cities in the southeast corner of Queensland, Australia.

We have presented most of the workshops in English (some with simultaneous translations into community languages), and we have experienced at least these two promising developments:

1) A number of community organizations asked if we could deliver the workshop as a training activity for their community liaison officers, who are typically in contact with migrant and refugee parents as well as with child care centres and community support agencies more generally.

2) A small university grant enabled us to hire and train facilitators to translate the workshop into a small number of minority languages and to adapt it for cultural appropriateness. These facilitators were members of their ethno-linguistic communities, employed by the Multicultural Development Association (MDA) as 'bilingual support workers', and hence were well connected with their fellow

\footnotetext{
${ }^{5}$ We were inspired by the initiative of Edwards and Newcombe (2006) to market Welsh/English bilingualism to prospective and new parents, with the support of midwives and health visitors. Our project is, however, very different from that one.
} 
community members. The facilitators, two female and one male, received one-to-one training by the workshop creators to delivered the content in their native languages, which included Amharic, Arabic, Madi and Samoan (emergent languages of southeast Queensland). English was used where other linguistic choices were highly sensitive to particular communities (e.g., the South Sudanese community preferred English to Arabic, which as a spill out of the conflict between the Arabic Muslim north and the Christian south, is perceived by the South Sudanese refugees as the language of their oppressors). Facilitators were responsible for recruiting participants from their community networks and delivered the workshops at community events and schools with a high number of students from the relevant community.

We expect these developments to help maximize the effectiveness of the workshop in reaching a wider migrant/refugee population.

Additional support is provided through our website Bilingualism (https://www.griffith.edu.au/humanities-languages/school-humanities-languages-socialscience/research/bilingualism). The site offers practical tips and links and includes promotional materials such as brochures on the free workshop in a variety of languages, and two downloadable flyers on the benefits of bilingualism, one for parents/carers and the other for educators.

\section{Aims}

The overall aim of the workshop is to promote maintenance and development of home language in migrant and refugee communities. This in turn involves inter-related aims that determine the workshop's content and structure. These include:

- To raise awareness of the benefits and challenges of bilingualism among parents and carers;

- To debunk myths surrounding bilingualism, thus assuaging fears and concerns;

- To empower parents in making informed decisions about their children's linguistic upbringing and give these parents tools to defend their decisions;

- To help develop practical strategies for achieving home language maintenance and development. 
Thus the content was organized around two main pillars: 1) disseminating information on bilingualism; and 2) providing practical ideas and tips for language maintenance and development.

\section{Content and Structure}

The workshop 'Should I speak English to my child?' is delivered in a highly interactive format. We present scenarios for group discussion so that participants can reflect on real cases and apply the abstract concepts and information we introduce to daily familiar situations. We also include ample examples of our personal experience raising our own bilingual children to reinforce that raising bilingual children is feasible and achievable and worthwhile, but also has its challenges.

The content has been designed around four central questions: Where, What, Why and How, which we briefly discuss in turn.

\section{Where?}

Here the aim is to normalize bilingualism by providing information about Australia's linguistic landscape. The materials covered in this section show that despite the monolingual mindset displayed by the Australian education system and societal attitudes more generally, bilingualism in Australia - as in most multiethnic societies - is the norm rather than the exception.

\section{What?}

This section, focusing on degrees and types of bilingualism, has two main aims. One is to help parents develop realistic expectations about the levels of proficiency their children can achieve. Having realistic expectations of success - rather than aiming for balanced bilingualism which is hard to attain - helps avoid frustration by focusing on what the child can do rather than of what they can't (cf. King and Fogle 2006; Piller 2001). The other aim is to describe and discuss different models of bilingual upbringing so that parents can evaluate the merits and challenges of each model and select a model suitable to their own family context.

Why? 
This section aims at empowering parents through knowledge, so that they can make informed decisions. Parents also need this knowledge to withstand societal pressure when asked to justify their choices. We begin this workshop section with demystifying bilingualism and debunking the most common myths surrounding bilingualism (e.g., the myths that 'children will mix languages if exposed to more than one' or 'their mainstream language will suffer'). We then move on to discuss the educational, cognitive, affective, professional and economic benefits that usually result from a bilingual upbringing, for children, parents, carers, communities and the mainstream society more generally. We also report on challenges that may be encountered in bilingual upbringing and how one might respond to these, and emphasize that raising children bilingually requires a lot of effort and commitment by the parents.

How?

This section aims at enhancing the experience of raising bilingual children by providing parents and carers with practical ideas on language maintenance and development, and advice on how to deal with situations in which children are reluctant to speak the home language. ${ }^{6}$

\section{Parents' feedback on the workshop}

Following some of the workshops, we asked parents and carers to complete an evaluation sheet to gauge their perceptions about the usefulness of the workshop and identify areas for improvement. ${ }^{7}$ The evaluation sheet contained both closed and open-ended questions. Our analysis of parental responses indicates that their views of the workshops were overwhelmingly positive. This applied even where the workshops have resulted in parents realizing that raising their children bilingually may be too high a goal to achieve in their family's current life situation. One mother reported verbally that after attending the workshop she felt happier, as she had lost her feeling of guilt and of being a failure for not raising her children bilingually, given her family’s situation at the time.

The following are some typical comments offered by parents on the evaluation sheet. Some parents reflected on the workshop and its value to them, the encouragement they experienced

\footnotetext{
${ }^{6}$ Several recent studies have considered the agentive role of children in shaping family language planning (e.g., Fogle 2013; Kheirkhah and Cekaite 2015; Lanza 2004). This issue was extensively discussed in the workshops, but it is outside of the scope of the paper which focuses on parents and carers perspectives.

${ }^{7}$ Please see Appendix for an example evaluation sheet.
} 
through it, and the information that we and all participants shared in it, as the following unedited quotes reveal:

(1) "This workshop is good and useful it encourages us not to forget our dialect, I urge every parent to teach or speak to their children in their own dialect while they are young. When they grow up they will always remember some words and they can be proud of who they are.”

(2) "This information is very useful and it should be delivered to families and the entire South Sudanese community in Brisbane, because some have abandoned their language and are only speaking English and Arabic only.”

Response (1) indicates that the respondents is aware the strong connection between home language maintenance and identity formation that we highlight in the workshops ("they can be proud of who they are”). Whether this realization stems from participating in the workshop or whether attendance to the workshop resulted from an already established commitment to bilingualism, however, cannot be ascertained based on their responses. Interestingly, (2) shows how different communities can attach different values to different languages (see Seloni and Sarfati 2013). The respondent appears to distinguish between what s/he thinks Australian society generally perceives as the South Sudanese community's mainstream languages, English and Arabic, and what is actually "their language" (i.e., Dinka). S/he has attached low emotional value to English and Arabic ("only speaking English and Arabic only”), but conveys the high importance of Dinka to community members' identity - referring to "their language” without naming it, and using the strongly connoted and value laden "abandoned". That children would still be growing up bilingually in these circumstances and would still be able to communicate successfully with members of their community (who all speak Arabic as the local lingua franca) appears to be of no relevance; what matter most to this respondent are identity and belonging.

Some parents commented on their own family and/or community practices:

(3) "In my family we speak our dialect to the children and everyone must speak when at home, though sometimes the children speak English among themselves but when communicating with us (parents) they use the dialect. I am happy Griffith has developed this program to encourage our community about their language.”

(4) “The Dinka community reported, we know the importance and the value of speaking own language and we are very grateful for this program. Most of our families speak 
Dinka to their children, we have organized classes for teaching those who have missed out and are interested to learn.”

Both comments outline some of the practices implemented in the family (parents expecting their children to speak the home language with them) and/or in the community (the community offering classes to children, in particular to those who are not exposed to the home language at home). The comments also indicate the participants appreciate both that the workshops encourage their efforts and that non-community members also value their home language. Both comments also show that these respondents were already well aware of the importance of home language maintenance prior to their workshop experience.

For some parents, the workshop experience reinforced their willingness to maintain the home language (comments (5) and (6)) and offered useful ways to help do so (reading books (5); staying the course, and creating both space and need for the language through using it consistently at home (7)):

(5) "I buy will the picture dictionary today and teach my children."

(6) "We those who were not speaking their language to the children or at home promised to start today."

(7) "Parents should not give up on their children even if they don't respond in the language, but should be consistency in speaking to them.”

The following quote from a participant expresses their regret that they were not exposed to their heritage language in childhood, a feeling that we have encountered in many non-English background, second generation adult Australians:

(8) "Speaking your language or other languages is precious but some never had the opportunity, because our parents never taught us we ended up speaking Arabic which is national language. Now I have children and can’t teach them my language because I don’t know. “

Comment (8), consistent with comment (2), shows the emotional value difference between people's home or heritage language - “my language” as speaker in (8) calls it, even though s/he does not know this language - and what is taken as the national language of their heritage country, in this instance Arabic. As we noted above, in the Australian context Arabic is another non-mainstream language and in this participant's context it is also the language of 
the oppressor of her/his heritage country. Identity and belonging are indeed amongst the most important issues coming up in our workshop discussions. In communities we have worked with, the professional and economic benefits of bi/multilingualism - often perceived to be of utmost importance in the mainstream society (see Piller's [2001] discussion on 'elite bilingualism') - pale in comparison to these key issues, becoming an added bonus rather than the main motivation for raising bilingual children.

The primary aim of these community outreach workshops was to empower participants and their families through knowledge, not to conduct a long-term study of language dynamics in participants' households. Thus, we have not followed up on participants to investigate whether participating in the workshop inspired or enabled families to actually put home language maintenance into practice. The positive responses of participants bode well, but we are aware that home language maintenance is a significant and a long-term commitment and researching the uptake of the workshops would require a longitudinal and multifaceted study in order to evaluate the effectiveness in terms of educational outcomes, linguistic development in both English and the home language, identity formation and well-being, and other relevant factors. Morever, family circumstances may prevent parents from raising children bilingually, even when they are armed with the best intentions. We do expect, however, that the information shared and discussed in the workshops helps parents and carers to decide on family language practices adapted to their own contexts, which from experience delivering the workshops we know are extremely diverse.

\section{Observations and lessons learned}

In this section, we summarize some observations and lessons we have learned in the course of offering and conducting the workshops. We also consider some of the recurring themes that participants raise, which are thus still of great importance to migrant/refugee parents and carers living in Australia.

One of the most important observations concerns those we are able to reach with the workshops, and those that we have not been able to reach. Generally, participants fall into one of two groups: those who see bi/multilingualism as an opportunity and a gift, and those for whom bi/multilingualism, or rather their children's ability to speak the home language, is a necessity. The opportunity group typically comprises well-educated parents whose motivation is to proactively inform themselves about current thinking in the field, to seek 
confirmation of their opinions and attitudes, to obtain practical ideas and guidance, and most importantly - to gain confidence or reassurance about their own approach. These parents' focus is on their children's long-term bilingual language development, in particular on the children's home language acquisition.

The necessity group, on the other hand, consists mostly of parents who are not yet fluent in mainstream English and hence attach great importance to English. They attend the workshops as a reaction to their own experiences, and often seek to troubleshoot problems they have encountered through their own journey, such as intergenerational conflicts or miscommunication due to linguistic barriers. Their motivation is to look for strategies for dealing with issues that have arisen. Rather than planning their language use in the home long-term and for the benefit of their children, their focus is on solving current practical problems. Parents with very basic skills in English have also often mentioned that they would like to speak more English at home, viewing this as opportunity for themselves to gain more exposure to English and to foster their own development of the English language with the help of their children. This contrasts with the practical necessity to communicate with their children in the home language, a tension they hope to resolve with the aid of the workshops. English plays a dominant role in these families' perceptions and the home language has a rather low level of priority, with all the potential ramifications of the children's eventual attrition from the home language.

Yet, it is important to note that for both groups the issue of their children's bi/multilingualism has gained enough importance and weight for the families to take steps. Even so, the societal situation outlined above shows that the majority of Australians, in particular those of monolingual mainstream Australia, do not show interest in the issue or are mostly unsupportive of linguistic diversity. Knowledge transfer and change of attitude on this issue requires reaching society as a whole. The workshops, while of great importance to interested individuals and communities, do not and presumably cannot accomplish attitudinal change in mainstream society.

In our experience, only a minority of non-English speaking background parents gives much weight to maintaining their children's home language. One of our recent workshops for parents was organized by a teacher in a state primary school where more than 70 percent of the students (about 200) have a non-English speaking background. Yet, only three parents 
came to the workshop, while more than two thirds of the teachers attended voluntarily. In addition to other pressures of daily life, parents often worry about their children's English and English literacy acquisition rather than their children's home language. They focus on educational outcomes and future success prospects for their children, as well as on their family's integration into society, which is typically closely linked to English proficiency. Thus, they do not see a need to educate themselves about bilingualism and the longer-term effects of their linguistic choices. We have observed many times, even with parents interested in the matter, that frequently they are unaware of the affective and social impacts of bi/multilingualism or its absence - for both the children and the family as a whole. Lack of information in the community means that attitudes generally are still based on misconceptions. For instance, child bilingualism is still seen by many as subtractive and hence not a worthwhile aim.

Many migrant/refugee parents see the focus on English not only as an economic necessity and a guarantor of academic success. Participant comments showed that they also recognize English language ability as a civic duty, showing one's respect to one's new country Australia. This is in line with a comment by Takahashi on Piller (2003):

It is also migrants themselves who come to invest heavily in the discourse of speaking English as a civic duty. I've had many conversations with new migrants in Australia, many of whom said that it's their duty to learn English, and those who do not want to, are disrespectful to the nation and thus should go back to where they came from. Linguistic policing among minority migrant groups is as concerning.

Hence, there is internal social pressure within some migrant communities to neglect or abandon their own language, again with all the ramifications of language attrition for the children and their families. More generally, social pressure appears to constrain parents from using their home language with their children outside of the home, or when non-home language speakers are present. Many parents reported being approached by well-meaning strangers advising them to speak English now that they are in Australia. These comments return us to the issue of lack of information in mainstream society and its effects: if mainstream attitudes on bi/multilingualism were well founded on scientific knowledge, parents speaking their home language with their children could presumably feel not apologetic but rather, proud of what they do. 
Another effect of this lack of knowledge is that child bi/multilingualism appears to become a scapegoat in some instances. If problems arise with bilingual children, it seems to be easy to attribute such problems to bilingualism. We have encountered this mainly in the context of perceived behavioural issues (which in most cases might just have been a result of the initial culture shock that the children experienced, or of different child rearing practices by child carers vs. parents) and perceived speech delays and/or disorders (which research knows are heavily over diagnosed in bilingual children). This builds up an unfortunate dichotomy of bilingual vs. 'normal' children, and we are aware it still results in a large number of cases where experts untrained in bi/multilingualism have advised parents to switch into English.

Last but not least, we feel that one more specific issue warrants brief mention. In families with only one home-language speaking parent, the role of the majority-language speaking parent should not be underestimated. There is evidence that the majority-language speaking parent plays an important role in the positive development of the home language (Venables, Eisenchlas and Schalley 2014). Working with different families, we have also experienced how the majority-language speaking parent can influence their child's non-mainstream language development very negatively, by for instance suppressing or prohibiting minority languages being spoken in the home. Moreover, in cases of relationship breakdowns, we have seen that the bilingual upbringing of children has been deliberately torpedoed by the majority-language speaking parent, although for at least one of the parents it was crucial for the child to learn the home language given this parent's low level of English proficiency. If equipped with more background information on bi/multilingualism one would hope that majority-language speaking parents would put their children's well-being over their relationship conflicts with their former partner, which again takes us back to the lack of information on bi/multilingualism in mainstream society.

\section{Conclusion}

The decision to transmit a minority language to one's offspring requires a strong will and long term commitment (Edwards and Newcombe 2005), particularly when this language is in competition with a global language such as English, ${ }^{8}$ whose command brings obvious benefits to proficient users. As we discussed briefly in the introduction, parents in Australia

\footnotetext{
${ }^{8}$ As noted above, despite what those who are hostile to bilingualism may claim, minority languages are not in competition with English, as revealed by community languages attrition rates reported in census data.
} 
generally encounter an unsupportive - if not outright negative - environment. Improving knowledge and attitudes towards bilingualism in mainstream society could motivate changes at the macro-level of language policy and facilitate parents' decisions to help their children towards this very valuable achievement. But we are skeptical that this change will eventuate any time soon in Australia.

We saw that it would be more promising for us to move from macro level to micro level, and it is at this level that we have initiated some grassroots activities. Finding support for bilingualism at this level has involved enlisting the assistance of people who deal with migrant/refugee families, such as early childhood educators, child care providers, teachers, health care providers, speech pathologists, and community liaison officers (via, e.g., inclusion of bilingualism-related topics in accreditation courses). This sends a message to parents that their home languages are recognized as valued resources, and helps to foment the 'homefamily-neighborhood-community' partnerships that Fishman (1991) and others saw as essential to reverse language shift.

In this paper we have focused on parents and carers of bilingual children, the first link in the partnership proposed by Fishman (1991). The workshop we developed and have discussed here stemmed from our strong belief that the benefits associated with bilingualism, identified in a significant body of research, are well worth the time and effort that parents and carers need to invest if they want to raise bilingual children. Regrettably, these uncontroversial findings have not trickled down to the wider population. We believe that parents would find it easier to make their decision about raising bilingual children if they were informed about the benefits of bilingualism, and had timely advice on best practices. We thus focused on translating research findings on the benefits and challenges of bilingualism to a wide and general audience, and on presenting these findings in concrete and practical ways that focus on the specific contexts and situations parents and carers may encounter in daily life.

As mentioned above, participants appreciated the workshops we have conducted. Most participants were parents and carers who already had a positive view of bilingualism and were seeking reassurance that their decision to maintain the home language was the right one as well as practical ideas to implement their decision. A challenge for us now is to expand the workshop to a wider population, so that the message is spread beyond 'the converted'. 
Another challenge is to identify how to ensure that stakeholders who deal with migrant and refugee families have access to information that enables them to offer informed advice where requested. This is the group that needs more convincing, but unfortunately we found that the second workshop we developed, aimed at educators and others in this group of stakeholders, generated little interest. We therefore conclude with a call for increased collaboration among all stakeholders as we work with one another to find realistic ways to support the bilingualism that already exists in society - in Australia and beyond - for the benefit of all.

\section{References}

Australian Bureau of Statistics. 2012. 2071.0 - Reflecting a Nation: Stories from the 2011

Census, 2012-2013. Retrieved from http://www.abs.gov.au/ausstats/abs@.nsf/mf/2071.0

Australian Bureau of Statistics. 2014. CensusAtSchool. Retrieved from http://www.abs.gov.au/censusatschool

Baldauf Jr, R. B. 1993. "Fostering Bilingualism and National Development through School Second Language Study.” Journal of Multilingual and Multicultural Development, 14 (12): $121-134$.

Barac, R., and E. Bialystok. 2011. "Cognitive Development of Bilingual Children.” Language Teaching, 44 (1): 36-54.

Bialystok, E. 2001. Bilingualism in Development: Language, Literacy, and Cognition. Cambridge: Cambridge University Press.

Bialystok, E., K. F. Peets, and S. Moreno. 2014. "Producing Bilinguals through Immersion Education: Development of Metalinguistic Awareness.” Applied Psycholinguistics, 35 (1): 177-191.

Chiro, G. 2014. "Cultural and Linguistic Diversity in Australia: Navigating between the Scylla of Nationhood and the Charybdis of Globalization.” International Journal of Multilingualism, 11 (3): 334-346.

Clyne, M. 2001. “Can the Shift from Immigrant Languages Be Reversed in Australia?” In J. A. Fishman, ed., Can Threatened Languages Be Saved? Reversing Language Shift Revisited: A 21st Century Perspective (pp. 364-391). Clevedon, Avon: Multilingual Matters.

Clyne, M. 2005. Australia's Language Potential. Sydney: UNSW Press.

Clyne, M. 2007. “Are We Making a Difference? On The Social Responsibility and Impact of the Linguist/Applied Linguist in Australia.” Australian Review of Applied Linguistics, 30 (1): 3.1-3.14. 
Cromdal, J. 1999. “Childhood Bilingualism and Metalinguistic Skills: Analysis and Control in Young Swedish-English Bilinguals Applied Psycholinguistics, 20 (1): 1-20.

Cummins, J. 2000. “Academic Language Learning, Transformative Pedagogy, and Information Technology: Towards A Critical Balance.” TESOL Quarterly, 34 (3): 537548.

Edwards, V., and L. P. Newcombe. 2005. "When School Is Not Enough: New Initiatives in Intergenerational Language Transmission in Wales.” International Journal of Bilingual Education and Bilingualism, 8 (4): 298-312.

Edwards, V., and L. P. Newcombe. 2006. "Back to Basics: Marketing The Benefits of Bilingualism to Parents.” In O. Garcia and T. Skutnabb-Kangas, eds., Imagining Multilingual Schools (pp. 137-149). Clevedon: Multilingual Matters.

Eisenchlas, S. A., A. C. Schalley, and D. Guillemin. 2013. “The Importance of Literacy in the Home Language: The View from Australia.” SAGE Open, October-December 2013, 1-14. DOI: $10.1177 / 2158244013507270$. Retrieved from http://sgo.sagepub.com/content/3/4/2158244013507270

Fogle, L.W. 2013. "Parental ethnotheories and family language policy in transnational adoptive families.” Language Policy 12(1). 83-102.

Fishman, J. A. 1991. Reversing Language Shift: Theoretical and Empirical Foundations of Assistance to Threatened Languages (Vol. 76). Clevedon, Philadelphia: Multilingual Matters.

Kheirkhah, M., and A. Cekaite. 2015. "Language maintenance in a multilingual family: Informal heritage language lessons in parent-child interactions.” Multilingua 34(3): 319346.

King, K. A., and L. Fogle. 2006. "Bilingual parenting as good parenting: Parents' perspectives

on family language policy for additive bilingualism.” International Journal of Bilingual Education and Bilingualism 9 (6). 695-712.

Lanza, E. 2004. Language Mixing in Infant Bilingualism: A Sociolinguistic Study. Oxford: Oxford University Press.

Lo Bianco, J. 2003. A Site for Debate, Negotiation and Contest of National Identity: Language Policy in Australia. Strasbourg: Language Policy Division, Council of Europe. Makin, L., J. Campbell, and C. Jones Diaz. 1995. One Childhood, Many Languages: Guidelines for Early Childhood Education in Australia. Pymble, NSW: Harper Educational. 
Queensland Government. 2009. "Smart Classrooms - Migrant Children Benefit from Digital Pedagogy.” In Education News. Retrieved from http://education.qld.gov.au/projects/educationviews/smartclassrooms/2009/may/immigrant s-090505.html

Piller, I. 2001. "Private language planning: The best of both worlds.” Estudios de Sociolingüística 2 (1). 61-80.

Piller, I. 2003. “Is Speaking English a Civic Duty?” Language on the Move blog. Retrieved from http://www.languageonthemove.com/is-speaking-english-a-civic-duty/.

Rosenthal, D. A., and A. M. Cichello. 1986. "The Meeting of Two Cultures: Ethnic Identity and Psychosocial Adjustment of Italian-Australian Adolescents.” International Journal of Psychology, 21 (1-4): 487-501.

Scarino, A. 2014. "Situating the Challenges in Current Languages Education Policy in Australia - Unlearning Monolingualism.” International Journal of Multilingualism, 11 (3): 289-306.

Schalley, A. C., D. Guillemin, and S. A. Eisenchlas. 2016. "Multilingualism and Assimilationism in Australia's Literacy-Related Educational Policies.” International Journal of Multilingualism, 12 (2): 162-177.

Seloni, L., and Y. Sarfati. 2013. "(Trans)national language ideologies and family language practices: a life history inquiry of Judeo-Spanish in Turkey.” Language Policy, (8). 7-26.

Swain, M., S. Lapkin, S., N. Rowen, and D. Hart. 1990. “The Role of Mother Tongue Literacy in Third Language Learning”. Vox, 4, 111-120.

Thomas, W., and V. Collier. 1997. School Effectiveness for Language Minority Students. Washington, DC: National Clearinghouse for Bilingual Education.

Valdés, G. 1995. “The Teaching of Minority Languages as Academic Subjects: Pedagogical and Theoretical Challenges.” The Modern Language Journal, 79 (3): 299-328.

Venables, E., S.A. Eisenchlas, S. A., and Schalley, A. C. 2014. “One-Parent-One-Language (OPOL) Families: Is the Majority Language- Speaking Parent Instrumental in the Minority Language Development?” International Journal of Bilingual Education and Bilingualism, 17 (4): 429-448.

Wright, S. C., and D. M. Taylor. 1995. "Identity and the Language of the Classroom: Investigating the Impact of Heritage Versus Second Language Instruction on Personal and Collective Self-Esteem.” Journal of Educational Psychology, 87 (2): 241-252. 


\section{APPENDIX \\ UNDERSTANDING BILINGUALISM - WORKSHOP EVALUATION}

Venue:

Date:

The following survey has been designed to evaluate your perceptions about this workshop. Please indicate your opinion by ticking the relevant box.

\begin{tabular}{|l|l|l|l|l|l|}
\hline & $\begin{array}{l}\text { Strongly } \\
\text { Agree }\end{array}$ & Agree & Neither & Disagree & $\begin{array}{l}\text { Strongly } \\
\text { Disagree }\end{array}$ \\
\hline $\begin{array}{l}\text { The content was } \\
\text { interesting }\end{array}$ & & & & & \\
\hline $\begin{array}{l}\text { The content was } \\
\text { relevant to my needs }\end{array}$ & & & & & \\
\hline $\begin{array}{l}\text { The explanations were } \\
\text { clear }\end{array}$ & & & & & \\
\hline $\begin{array}{l}\text { The workshop was well } \\
\text { presented }\end{array}$ & & & & & \\
\hline $\begin{array}{l}\text { There were many } \\
\text { opportunities to ask } \\
\text { questions }\end{array}$ & & & & & \\
\hline $\begin{array}{l}\text { I feel more confident } \\
\text { now about my } \\
\text { understanding of } \\
\text { bilingualism }\end{array}$ & & & & & \\
\hline $\begin{array}{l}\text { I got many ideas and } \\
\text { tips to foster } \\
\text { bilingualism }\end{array}$ & & & & & \\
\hline $\begin{array}{l}\text { Overall, I am satisfied } \\
\text { with this workshop }\end{array}$ & & & & & \\
\hline
\end{tabular}

What were the most positive aspects of the workshop? 
What could be improved?

Thank you for your feedback! 